\title{
Dealing With Accuracy in Communicative Language Teaching
}

\author{
Wendy Allen and Sue Waugh
}

For practitioners interested in making principled decisions about what and how to teach; the implementation of any new approach presents dilemmas for which there are no clear answers. Theoretical knowledge, insights from experience and practical considerations all go into formulating hypotheses and developing techniques and materials to solve these problems. In this paper we will discuss some of these issues as they relate to the problem of accuracy within the communicative approach and present the selfassessment unit we developed to deal with the problem in our program.

Language teaching methods differ in the way grammar is presented and the prescriptions for dealing with errors. This reflects underlying ideas about language learning. For example, understanding rules and applying them in translation exercises is consistent with a view of language learning as academic knowledge (grammar-translation); imitating and manipulating grammatical structures reflects a habit formation theory of language learning (audiolingual approach). In grammar-translation, the teacher is responsible for correcting errors in a written text; in the audiolingual approach, the teacher tries to prevent errors from occurring by presenting structures systematically, and if this fails, to correct them so that they do not become bad habits.

The communicative approach is based on different assumptions about language learning. These assumptions in turn have implications for dealing with accuracy. However, at the present stage of development of the communicative approach, this is still an area of great confusion. Many practitioners continue to use the same techniques they used with the audiolingual approach, justifying this in the name of eclecticism. But eclecticism should refer to techniques, not principles. If principled solutions are to be found, old techniques must be re-examined. If they are inconsistent with current theory, they may need to be adapted or discarded. Innovative techniques may also be needed.

In the first section of this paper we will outline our theoretical position on communicative competence, language acquisition and autonomy as they relate to the issue of accuracy. In the second section we will present the "Linguistic Competence" unit, one of three in a self-assessment module which was developed to help intermediate/advanced learners focus on accuracy. 


\section{COMMUNICATIVE COMPETENCE}

\section{Is linguistic competence part of communicative competence?}

The role of linguistic competence within communicative competence has often been misinterpreted or misrepresented. While "getting your idea across by any means" may be an appropriate pragmatic strategy in specific contexts, the model underlying our materials includes linguistic competence as well as sociolinguistic and discourse competence as intrinsic parts of communicative competence (Canale, 1981).

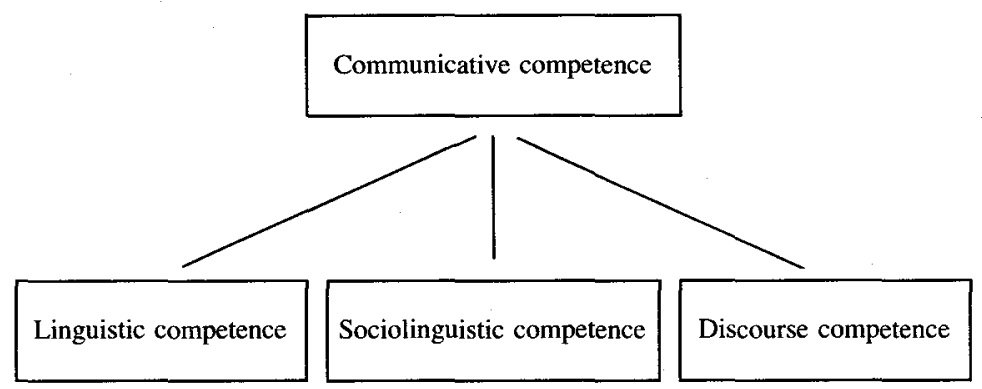

This model represents an idealization; not even native speakers have $100 \%$ competence in all areas in all contexts. However, the model acknowledges the role of linguistic competence within the larger goal of communicative competence for native and non-native speakers of any language.

Is the importance of accuracy based only on comprehensibility?

There are two kinds of comprehension problems that result from errors. The first is when the listener does not understand what the speaker is trying to say (communication breakdown), which usually disappears as general competence improves. The second kind of problem is due to errors which result in misunderstanding or ambiguity. For example:

"You are requested to assist at a meeting"

Here assist could be interpreted as help or attend (from French assister). This second kind of problem continues to affect comprehensibility at a more advanced level.

However, not all linguistic errors affect comprehensibility. Also typical of the intermediate learner are errors which are simply irritating to the listener (Johansson, 1975; Piazza, 1976; Tardif \& d'Anglejan, 1981). Examples of these are subject-verb agreement or incorrect forms 
of past participles. The degree of irritation caused by grammatical errors is also influenced by their number and frequency and by the attitude of the listener. Irritating errors can result in impatience (Why can't s/he get it right?) or negative judgements about the intelligence or social class of the speaker. Another consequence could be that the listener decides not to make the extra effort required to interpret non-standard forms.

Our interpretation of Communicative Language Teaching is that the importance of communicating the message is stressed at all stages of ESL learning. At the beginner's level this involves the use of compensatory strategies; errors that do not cause communication breakdown are not a focus for concern. However, with high-intermediate learners who can get their message across by one means or another, accuracy is seen as the fine tuning necessary to refine communication skills.

Does the importance of accuracy vary from learner to learner and from task to task?

Some learners may want a higher overall level of accuracy. This could be related to their role, personality, or objectives. For example, a second language speaker who teaches English in an EFL context will be a model for correct English. Individuals with certain personality types avoid speaking if they cannot speak with a high degree of accuracy. There are also learners who want or need to be integrated into an English-speaking context. In order to do this they may require a high degree of accuracy to fulfil their duties successfully, to be accepted as peers and to meet personal objectives.

The importance of accuracy may also vary for the same learner when doing different tasks. This can depend on how important it is to transmit the message precisely, and the degree of accuracy that this requires. The level of accuracy needed may also depend on whether or not there is a sympathetic interlocutor and how much negotiation $s /$ he is willing to do. For example, a suspect questioned by a Royal Canadian Mounted Police officer may be unwilling to work very hard to understand him/ her, while someone registering a complaint may likely have a much higher interest in understanding and being understood.

\section{ACQUISITION}

Is it necessary to correct learners' errors?

One of the teachers' greatest frustrations in correcting learners' errors is to find them reappearing uncorrected. Habit formation models of lan- 
guage acquisition made it our duty to police any grammatical rule breaking. Yet it often seemed a thankless and fruitless task. In this context Krashen's prediction (1976) that errors would take care of themselves as the learners' grammar was refined through exposure to sufficient comprehensible input was welcomed and it has had a considerable impact on communicative methodology. The use of authentic input which is ungraded in grammatical terms and the laissez-faire attitude to errors that do not interfere with communication advocated in communicative methodology are both consistent with Krashen's hypothesis. Within this framework the answer to the question "Is it necessary to correct learners' errors?" would be "No."

However, experience continually provides teachers with evidence that errors do not necessarily disappear even as the learners appear to be able to comprehend more and more complex grammatical forms. Among the articles that have appeared recently criticizing Krashen's Monitor Model and the implications that relate to teaching methodology (Gregg, 1984; White, $1985^{1}$ ) is a critique by Clifford and Higgs (1982) that concludes that the communicative approach promotes the fossilization of errors. They describe a "terminal $2+$ " profile ${ }^{2}$ : even when other categories such as fluency and vocabulary reach 4 on the scale, grammatical accuracy shows no improvement beyond $2+$. As a result, they reject the communicative approach and advocate a return to controlling structures and correcting errors. Given that the undisputed goal of ELT is communicative competence, this solution would only make sense if there was evidence that their solution had a significant effect on a learner's performance in uncontrolled situations. And, in fact, there is evidence to the contrary, which is where Krashen started. That is, learners may appear to have mastered a structure under certain conditions such as pencil and paper task. However, when using these same structures in communicative situations, errors occur. Krashen's claim is that learning (conscious knowledge of linguistic rules) does not affect acquisition (the internalization of linguistic rules). Another problem with this solution is that it would have to be implemented before fossilization occurs. This would mean that there would be little we could do for learners with " $2+$ profiles" who come for language training.

It may be that certain problems can be dealt with successfully with specific techniques that have been around for a long time. But what is needed from ESL teachers and applied linguists is more research on the effectiveness of techniques that were used in structure-based teaching in terms of the goals of communicative language teaching. Also needed is the development of new techniques which are theoretically consistent with current hypotheses about language acquisition and the principles of communicative language teaching. 
What considerations underlie the use of self-assessment as a technique for dealing with accuracy?

Experience with having learners identify their own errors reveals that errors fall into three categories:

1) errors that learners can identify and correct

2) errors that learners can identify but not correct

3) errors that learners cannot or do not identify

We hypothesize that this hierarchy provides important information about the learner's internalized grammar and communicative needs. Our proposal is that the errors in first and second categories which are identified by the learner should provide the content for an individualized syllabus. This proposal challenges Krashen's learning/acquisition dichotomy since it is based on the assumption that learning can affect acquisition under certain conditions, the condition in this case being that having learners identify their own errors will provide the necessary focus and motivation to improve accuracy.

\section{AUTONOMY}

What are the advantages of having learners take responsibility for identifying their own errors?

In addition to the advantage of individualization, which is related to the learner's readiness and motivation, helping students take responsibility for their learning is one of the goals of education in general. It is particularly relevant for adult learners. Providing learners with tools to identify needs, set objectives and develop higher levels of communicative competence must be a goal of communicative language teaching if it is to deal with language in use and learners' changing needs and permit them to continue learning once formal language training is completed. Prevalent attitudes to error correction, which give the responsibility for correction to the teacher, can be seen as contradictory to the goal of autonomy. Our claim is that the student can learn to identify errors and find ways to correct many of them in consultation with the teacher. This training would be part of the autonomization process which would ultimately prepare learners to take responsibility for their own learning.

\section{LINGUISTIC COMPETENCE-A SELF-ASSESSMENT UNIT}

In this part of the paper we will discuss materials developed for dealing with accuracy that reflect the theoretical considerations discussed 
previously. The Linguistic Competence unit was designed for Francophone Royal Canadian Mounted Police officers who are required to work and live in an English community after completing formal language training. However, the techniques could be used in any situation involving adult high-intermediate/advanced learners who have no trouble getting their message across, but who need to improve their accuracy. The two main objectives of the unit are:

- to sensitize learners to the effect of errors in order to motivate them to work on accuracy

- to initiate the process of autonomization so learners will be equipped to continue working on accuracy once formal language training has ended

In order for learners to achieve these two objectives the unit is divided into two phases:

- a sensitization phase in which learners are made aware of the effect of errors

- a self-assessment phase in which learners identify their own errors and make decisions about what errors they are going to focus on

The objective of Task 1 is to show learners that errors do "cost". Learners work in small groups, listen to three second language speakers of French on audiocassette and make subjective judgements about the proficiency of these second language speakers.

\section{Task 1: Determining the cost of errors in French}

Assessing speakers of French as a second language is one way of illustrating that the cost of errors can vary from speaker to speaker and situation to situation. How a second language speaker is perceived by a native speaker depends on many factors.

\section{Instructions}

With another student pick an audiocassette and listen to the speakers of French as a second language. Give each speaker a rating between one and five (five = native speaker proficiency).

List the factors that influenced your decision (topic, number of errors, kind of errors, frequency of an error, ideas expressed by the speaker, etc.).

What problem area would you have them focus on?

What specific errors would you have them work on?

What one piece of advice would you give them?

Finally, rank the speakers from best to worst. 
Factors:

Area to improve in:

Specific errors

to work on:

Advice:

Having learners begin by making judgements about second language speakers of French is a non-threatening way of getting them to think about the effect that errors can have.

In Task 2, the objective is to have learners focus on how a certain type of error might be perceived by native speakers. This task builds on Task 1 by having learners use their ideas from that task to discuss the questions raised in Task 2 .

\section{Task 2: Assessing the cost of errors}

\section{Instructions}

You have now made subjective judgements about speakers of French as a second language. Using your impressions of these speakers and your own experience, consider the following sentences involving second language speakers and decide how their language problems might affect the way they are perceived by a native speaker. In small groups discuss:

- how a second language speaker with a strong accent would be perceived by a native speaker.

- how a second language speaker who makes a lot of grammatical errors would be perceived by a native speaker.

- how a second language speaker might be perceived by educated native speakers if he makes certain kinds of grammatical errors. For example:

Si j'aurais de l'argent, j'irais en vacances.

T'as-tu le dossier sur l'affaire Sirois?

$J$ 'vas vérifier ça tout de suite.

He didn't do nothing wrong.

He don't know.

He should've went.

- how a second language speaker would be perceived by a native speaker if he uses the wrong word. For example: 
J'aimerais introduire les deux conférenciers invités.

Mes élèves sont des adultes qui ont entre 30 et 40 ans.

I know your time is expensive.

My boss assisted a meeting yesterday regarding new employees.

He's going to pay me a beer.

In Task 3, the goal is to have learners develop sensitivity towards errors in their second language. Learners repeat the procedure they followed in Task 1, this time making judgements about the proficiency of second language speakers of English. (A sheet with native speaker opinions appears in the Teacher's Guide so that learners can compare their judgements with those of native speakers.) In this task learners also discuss other factors related to the cost of errors. Part B has learners consider errors in relation to the irritation they cause.

In small groups, discuss the following:

- the effect of a message which is completely comprehensible but contains errors.

- the kinds of errors that are the most irritating.

- the kinds of errors that make it difficult to understand what the person is saying.

- the effect of an error that is frequently repeated in a short space of time. (For example, an Anglophone speaking French who always pronounces the final consonant of a word.)

- the effect of a message where there is an error in almost every second word.

- the effect of errors in written versus oral communication. (What kinds of errors will be the most offensive in writing?)

- the kinds of errors that will be the most costly in each of the following situations. (In which situation will errors be the most serious?)

- giving facts in court.

- interrogating a citizen.

- interviewing a citizen for a security check.

Task 4 is the beginning of the self-assessment phase. Learners first decide whether they want to focus on accuracy in speaking or writing. Then they listen to a tape where they were involved in a communicative activity or examine something they have written (e.g., memo, letter, report). They are asked to identify their errors and correct them if they can. They also give themselves a rating on a five-point scale, with 5 as native-speaker proficiency. Then each learner decides, in consultation with the teacher, what specific errors $s /$ he is going to focus on, how $\mathrm{s} /$ he will go about working on them and what form of evaluation will be used to see if the objectives have been met. 
Some ideas are given to learners for ways in which to approach the first two categories of errors (those they can identify and correct and those they can only identify).

In order to focus on your specific errors, it is important to identify the specific situation where the error occurs. If you don't know what the rule is, it would be a good idea to do some preparatory work first.

For example, if you didn't know when to use 'had + verb' (for reported speech), when writing an occurrence report, you might want to study the rule and so some exercises first before moving on to actually writing occurrence reports.

If you are focussing on a problem where you know the rule but still make errors when communicating, it would be best to work directly in the type of communicative situation where the error occurs. For example, if you had trouble using questions like "Where would he have gone? Would he have taken the collection with him?" when interviewing or interrogating, it would be advisable to role-play or simulate these types of situations as part of your plan to work on monitoring for this particular error.

Learners review their objectives at the end of every week with the teacher and decide whether to continue with the same objective or whether to set a new one.

\section{FEEDBACK FROM TRIALS}

The sensitization phase of the unit has been done by the RCMP pilot group and by two classes from Revenue Canada. The following comments were made by students during this phase:

"It's important to know what other people around you have to suffer when you learn a second language. This makes us understand how people judge us."

"Gee, maybe English people look at us the same way when we speak English."

The self-assessment phase was tried with the RCMP group for a fourweek period, with tourism students from the Institut de tourisme et d'hôtellerie du Québec and with a Université de Montréal immersion program in Vermont. It is to be used by classes at Revenue Canada and the Advanced Language Training Program of the Public Service Commission. Examples of a few of the problems learners identified and the methods they chose to deal with them are described below.

\section{Student 1}

problem: The student watched a simulation where he was checking 
a boater to see if boating safety regulations were being followed. He identified his lack of technical vocabulary as his principal problem.

method: He proposed compiling a vocabulary list using the Ministry of Transport booklet on boating safety, practicing the pronunciation of the terms and then redoing the simulation the following week. He was satisfied that he had made some improvements in the second simulation.

Student 2

problem: The student identified the use of the present perfect tense in writing business letters as a problem.

method: He wanted to learn the rules for the present perfect, to write business letters monitoring for the use of the present perfect and to get feedback from the teacher. His use of the present perfect in business letter writing improved substantially.

Student 3

problem: The student decided to focus on the 3rd person singular and plural forms of nouns after getting feedback from a native speaker who said he found the missing " $\mathrm{s}$ " irritating.

method: He suggested that he read aloud using texts where this form occurred. However, when he read, the "s" was also eliminated which led us to hypothesize that there was interference from French where word-final "s" in written French is not pronounced (except before a vowel). In addition it turned out that he did not know the rules. Once the rules were clarified, he decided to select topics (which required the use of the present tense, especially the 3rd person form and plurals) which he would talk about for five minutes a day while recording himself. This was a long-term project, and formal language training ended before any clear improvements could be noted.

\section{Student 4}

problem: The student identified the pronunciation of job-related vocabulary as a problem after listening to her presentation about a European tour.

method: She listed the words that presented difficulty. Then she acted on a suggestion to do some exercises using Clear Speech in order to help her understand some of the prin- 
ciples of English pronunciation. She then had the vocabulary items she had identified as problematic recorded by a native speaker. She practiced these items checking with the teacher if she was unsure of the pronunciation. Finally, she redid her presentation showing considerable improvement.

\section{Student 5}

problem: The student identified the use of articles for the names of places and tourist attractions as problematic after listening to a recording of himself giving directions in Montreal.

method: First he listed the problematic items and the teacher provided the correct forms. The student than spent some time trying to systematize the rules that applies using Avoiding Article Traps. He then re-recorded the directions in Montreal and tried to do a similar set of directions in Vancouver. This was only moderately successful but the learner was sensitized to the fact that while there are rules for articles, they are only of limited use. He concluded that he had to focus on learning the article along with the names of places and attractions.

\section{CONCLUSION}

More experimentation and documentation are needed on the use of this technique. Teachers now using the materials are keeping an account of student responses to the materials, to self-assessment and to the problems and methods they use to deal with them. Teachers are also recording their own reactions and problems particularly in regards to their role as counsellors/tutors. However, this kind of information is not enough to provide credibility for this approach to accuracy. The emphasis on data-based research in North America requires that carefully designed studies show that accuracy improves. However, teaching institutions rarely have the personnel and funding needed to carry out this research. What is needed is more interaction between ESL practitioners and applied linguists so that problems dealt with by the practitioners can be provided with the support of applied linguistic research.

\section{NOTES}

1. Some applied linguists such as White are looking for theories with predictive power to provide a principled approach to the problem. In her paper "Against comprehensible input: the input hypothesis and the development of L2 competence" she discusses two cases where change cannot be motivated by semantic or extra-linguistic cues 
(which is what Krashen's Input Hypothesis depends on). An example of the first case would be the 3rd person singular $s$ morpheme or an irregular past form like went. Normal input will likely contain examples that contrast with the learner's form providing motivation for change (rule addition). These errors could be identified by the learner. Whether the language teacher can provide a shortcut "either by means of correction or the teaching of exceptional forms" is open to question. The second case, however, is where the learner makes an overgeneralization which requires a rule deletion. In these cases there is nothing in the input that would indicate the non-occurrence of the form.
John gave some money to the hospital.
John gave the hospital some money.
John donated some money to the hospital.
* John donated the hospital some money.

The hypothesis is that the overgeneralization is due to the existence of the rule in the first language which will only be deleted if there is negative evidence for the form's occurrence in the second language (i.e., Since we can generate grammatical sentences without having ever heard them, a learner would not have to conclude that a sentence $\mathrm{s} /$ he generates is ungrammatical just because $s /$ he has never heard a native speaker say it. Negative evidence, then, is not provided by the absence of the form in the input.) White suggests that language teachers would have to provide negative data or teach specific structures in cases like the one given in the example. There is no way learners could identify these errors. However, which structures to teach and to whom requires that well-motivated hypotheses be proposed and tested. This is a long-term project that has exciting potential.

2. The Foreign Service Institute evaluates speaking performance on a 5-point scale with midpoints at each level indicated by + . Native speaker proficiency is rated 5 . Speakers are evaluated for pronunciation, fluency/integrative, sociolinguistic/culture, grammar, vocabulary and tasks.

3. See McLaughlin (1978) and Gregg (1984) for arguments against the learning/acquisition dichotomy.

\section{REFERENCES}

Allen, W. \& Waugh, S. (1984). Linguistic Competence, Self-assessment Module, RCMP In-Service Language Training, Program. Ottawa: Department of Supplies and Services of Canada.

Canale, M. (1981). From communicative competence to communicative language pedagogy. In Jack Richards \& Richard Schmidt (Eds.), Language and Communication. London: Longman Group Ltd.

Gilbert, J.B. (1984). Clear Speech: Pronunciation and Listening Comprehension in American English. Cambridge: Cambridge University Press.

Gregg, K.R. (1984). Krashen's monitor and Occam's razor. Applied Linguistics. $5(2), 79-100$.

Gremmo, M. \& Abbe, D. (1983). Enseignement/apprentissage: vers une redéfinition du rôle de l'enseignant. Mélanges pédagogiques.

Guide pédagogique Secondaire: Anglais langue seconde. (1984). Ministère de l'Education, Gouvernement du Québec.

Higgs, T.V. \& Clifford, R. (1982). The push toward communication. In Curriculum, Competence and the Foreign Language Teacher. The SCTFL Foreign Language Education Series. Skokie, Ill.: ACTFL. 
Hymes, D. (1972). Models of the interaction of language and social life. In John Gumperz \& Dell Hymes (Eds.), Directions in Sociolinguistics. Holt, Rinehart and Winston.

Johansson, S. (1975). "Problems in studying the communication effect of learners' errors". Photocopy. Unpublished manuscript, Université de Lund.

Krashen, S. (1981). Second Language Acquisition and Second Language Learning. Oxford: Pergamon Press.

Krashen, S. (1979). A response to McLaughlin, "The Monitor Model: Some methodological considerations", Language Learning, 29(1), 151-167.

Krashen, S. (1976). E.S.L. as Post-Critical Period Learning. Paper presented at the 1976 MEXTESOL Conference, October 15, 1976.

Lightbown, P., Spada, N. \& Wallace R. (1980). Some effects of instruction on child and adolescent ESL learners. In Robin Scarcella and Stephen D. Krashen (Eds.). Research in Second Language Acquisition. Rowley, Mass: Newbury House.

McLaughlin, B. (1978). The Monitor Model: Some methodological considerations. Language Learning, 28(2), 309-332.

Mills, Geoffrey (1976). Avoiding Article Traps. Ministry of Supply \& Services Canada.

Piazza, L.G. (1976). Communicative effects of grammatical errors made by Americans learning French. Unpublished doctoral dissertation, the University of Rochester, Rochester, New York.

Savignon, S.J. (1983). Communicative Competence: Theory and Classroom Practice. Reading, Mass.: Addison-Wesley.

Selinker, L. (1972). Interlanguage. IRAL IO(3), 209-231.

Stevick, E.W. (1980). The Levertov machine. In Robin Scarcella \& Stephen D. Krashen (Eds.). Research in Second Language Acquisition. Rowley, Mass.: Newbury House.

Swain, M. \& Canale, M. (1980). Theoretical bases of communicative approaches to second language teaching and testing. Applied Linguistics, I(1).

Tardif, C. \& d'Anglejan, A. (1981). Les erreurs en français langue seconde et leurs effets sur la communication orale. The Canadian Modern Language Review. 37(4), 706.

White, L. (1985). "Is there a 'Logical Problem' of Second Language Acquisition?" TESL Canada Journal 2(2), 29.

White, L. (1985b). Against comprehensible input: the Input Hypothesis and the development of L2 competence. Paper presented at Lars, Utrecht, September, 1984.

\section{THE AUTHORS}

Wendy Allen is presently working for the Public Service Commission on the development of self-access, work-related materials. She was the project developer for the RCMP In-Service Language Training Program.

Sue Waugh is presently at George Brown College as manager of an EWP project "Improving Communications in the Hospitality Industry". She has worked at the Public Service Commission as a teacher/materials writer on the RCMP Project and as a test developer for Tests, Measurements and Evaluation. 